Research Article

\title{
Clinicopathological Characteristics and Prognosis of Upper Gastric Cancer Patients in China: A 32-Year Single-Center Retrospective Clinical Study
}

\author{
Yingbo Gong $\mathbb{D}^{1,2}$ Pengliang Wang, ${ }^{1,2}$ Zhi Zhu $\mathbb{D}^{1,2}$ Junyan Zhang, ${ }^{1,2}$ Jinyu Huang, \\ and Huimian $\mathrm{Xu} \mathbb{1 D}^{1,2}$ \\ ${ }^{1}$ Department of Surgical Oncology, The First Hospital of China Medical University, 155 Nanjing North Street, Heping District, \\ Shenyang 110001, China \\ ${ }^{2}$ Key Laboratory of Gastric Cancer Molecular Pathology of Liaoning Province, 155 Nanjing North Street, Heping District, \\ Shenyang 110001, China
}

Correspondence should be addressed to Huimian Xu; xuhuimian@126.com

Received 22 August 2019; Accepted 4 November 2019; Published 1 December 2019

Academic Editor: Fausto Rosa

Copyright (c) 2019 Yingbo Gong et al. This is an open access article distributed under the Creative Commons Attribution License, which permits unrestricted use, distribution, and reproduction in any medium, provided the original work is properly cited.

\begin{abstract}
Purpose. Upper or proximal gastric cancer occurs in the upper third of the stomach between the cardia and a line connecting the greater and lesser curvatures. As it differs from other gastric cancers in pathology and prognosis, we evaluated patient and disease characteristics that might guide improved treatment and survival of upper gastric cancer. Methods. We conducted a retrospective analysis of 649 patients with upper gastric cancer and 1551 patients with lower gastric cancer and R0 radical surgery at our institution between January 1980 and December 2012. Results. Survival after radical surgery for upper gastric cancer was $77.8 \%$ at 1 year, $49.6 \%$ at 3 years, and $41.1 \%$ at 5 years. The corresponding rates for lower gastric cancer were $85.9 \%, 60.0 \%$, and $57.2 \%$ $(p<0.001)$. Upper gastric cancer had a poor prognosis. Sex $(p=0.036)$, tumor diameter $(p=0.001)$, macroscopic type $(p<0.001)$, pTM stage $(p<0.001)$, tissue differentiation type $(p=0.003)$, and serosal invasion $(p=0.034)$ were independently associated with lymph node metastasis. The macroscopic type $(p=0.045)$, lymphovascular tumor emboli $(p=0.021)$, and pTNM stage were independently associated with recurrence and metastasis. Survival of 333 patients with D2 total gastrectomy was $81.3 \%$ at 1 year, $54.4 \%$ at 3 years, and $45.2 \%$ at 5 years. The corresponding rates for 316 proximal gastrectomy patients were $75.4 \%$, $44.9 \%$, and $36.7 \%$. Radical total gastrectomy had better survival than radical proximal resection. Conclusions. Upper gastric cancers were more aggressive, had a worse prognosis, and were more prone to recurrence and metastasis compared with lower gastric cancers. Survival was better after total gastrectomy than after proximal resection.
\end{abstract}

\section{Background}

Gastric cancer is the sixth most prevalent malignant tumor worldwide and the third leading cause of cancer-related deaths. The International Agency for Research on Cancer estimated that there were about one million new cases of gastric cancer and 782685 deaths from gastric cancer in 2018 [1]. Upper gastric cancer, also known as proximal gastric cancer, occurs below the cardia and above a line connecting the greater and lesser curvatures, and its incidence is increasing $[2-5]$. The epidemiology, pathology, surgical treatment, and prognosis of upper gastric cancer differ from those of lower stomach cancer. Its anatomical location makes upper stomach cancer relatively difficult to find, and it lacks specific symptoms at early stages of disease. Diagnosis at a mid or late stage increases the difficulty of treatment and leads to a poor prognosis $[4,6,7]$. An evaluation of dysphagia may lead to an early diagnosis $[8,9]$. At present, the choice of surgical treatment has changed from simple anatomy to oncology biology, immunology, and anatomy. The clinical and pathological characteristics of individual upper gastric cancer patients may be of value in choosing surgical options that will improve survival. Radical surgery is currently the most effective treatment, but the extent of lymph node dissection and 
TABLE 1: Clinicopathological characteristics of patients with upper and lower gastric cancer.

\begin{tabular}{|c|c|c|c|}
\hline & $\begin{array}{l}\text { Upper gastric cancer (\%) } \\
\qquad n=649\end{array}$ & $\begin{array}{l}\text { Lower gastric cancer (\%) } \\
n=1551\end{array}$ & $p$ value \\
\hline Sex & & & $<0.001$ \\
\hline Male & $531(81.8)$ & $1098(70.8)$ & \\
\hline Female & $118(18.2)$ & $453(29.2)$ & \\
\hline Age (years) & & & 0.003 \\
\hline$<60$ & $303(46.7)$ & $833(53.7)$ & \\
\hline$\geq 60$ & $346(53.3)$ & $718(46.4)$ & \\
\hline Tumor diameter $(\mathrm{cm})$ & & & $<0.001$ \\
\hline$<5$ & $267(41.4)$ & $946(61.0)$ & \\
\hline$\geq 5$ & $382(58.9)$ & $605(39.0)$ & \\
\hline Tissue type & & & 0.046 \\
\hline Well differentiated & $270(41.6)$ & $575(37.1)$ & \\
\hline Poorly differentiated & $379(58.4)$ & $976(62.9)$ & \\
\hline Tissue growth mode & & & $<0.001$ \\
\hline Agglomerate type & $131(20.2)$ & $434(28.0)$ & \\
\hline Nest type & $185(28.0)$ & $467(30.1)$ & \\
\hline Diffuse type & $333(25.7)$ & $650(41.9)$ & \\
\hline \multicolumn{4}{|l|}{ Macroscopic type } \\
\hline Early & $47(7.2)$ & $332(21.4)$ & $<0.001^{*}$ \\
\hline Local (Borrmann 1, 2) & $126(19.4)$ & $212(13.7)$ & $0.068^{\#}$ \\
\hline Infiltrative (Borrmann 3, 4) & $476(73.4)$ & $1007(64.9)$ & \\
\hline $\mathrm{pT}$ & & & $<0.001$ \\
\hline $\mathrm{T} 1$ & $47(7.2)$ & $331(21.3)$ & \\
\hline $\mathrm{T} 2$ & $67(10.3)$ & $318(20.5)$ & \\
\hline $\mathrm{T} 3$ & $271(41.8)$ & $527(34.0)$ & \\
\hline $\mathrm{T} 4 \mathrm{a}$ & $224(34.5)$ & $340(21.9)$ & \\
\hline $\mathrm{T} 4 \mathrm{~b}$ & $40(6.2)$ & $35(2.3)$ & \\
\hline $\mathrm{pN}$ & & & 0.041 \\
\hline No & $232(35.7)$ & $639(41.2)$ & \\
\hline N1 & $116(17.9)$ & $299(19.3)$ & \\
\hline $\mathrm{N} 2$ & $138(21.3)$ & $284(18.3)$ & \\
\hline N3a & $110(16.9)$ & $235(15.2)$ & \\
\hline $\mathrm{N} 3 \mathrm{~b}$ & $53(8.2)$ & $94(6.1)$ & \\
\hline Lymphovascular tumor embolus & & & 0.034 \\
\hline Positive & $172(26.5)$ & $346(22.3)$ & \\
\hline Negative & $477(73.5)$ & $1205(77.7)$ & \\
\hline Serosal invasion & & & $<0.001$ \\
\hline Positive & $264(40.7)$ & $375(24.2)$ & \\
\hline Negative & $385(59.3)$ & $1176(75.8)$ & \\
\hline Recurrence and metastasis & & & $<0.001$ \\
\hline Positive & $277(42.7)$ & $526(33.9)$ & \\
\hline Negative & $372(57.3)$ & $1025(66.1)$ & \\
\hline
\end{tabular}

*Early versus advanced cancer; ${ }^{*}$ comparison of advanced cancers.

the optimal surgical procedure may not be easy to determine [10-12]. The objective of this retrospective analysis of patient characteristics, surgical treatment, and cancer prognosis was to identify clinical, pathological, and surgical variables that were associated with improved outcomes, prognosis, and survival of those with upper gastric cancer.

\section{Patients and Methods}

2.1. Patient Selection and Study Design. A group of 2200 patients with radical surgery for gastric cancer at The First Hospital of China Medical University, Shenyang, Liaoning, China, between January 1980 and December 2012 were 
retrospectively evaluated. Patients with a postoperative pathological diagnosis of primary gastric adenocarcinoma, no other history of gastric surgery, no neoadjuvant therapy before surgery, and no preoperative imaging evidence of distant metastasis were eligible. All surgeries were R0 resections; postoperative pathology was evaluated by two experienced pathologists. The lymph node grouping, transfer site, and numbers were included in the pathology report. All included patients had complete follow-up data, and there was no loss of follow-up. Of the 2200 included patients, 649 had upper gastric cancer and 1551 had lower gastric cancer.

2.2. Pathological Criteria. The macroscopic pathology included Borrmann types 1 and 2 for local and Borrmann types 3 and 4 for infiltrative disease. Tissue growth was classified as agglomerate, nest, or diffuse. Tissue typing included highly and moderately differentiated papillary adenocarcinoma and well- and poorly differentiated tubular adenocarcinoma. Signet ring cell carcinoma, mucinous adenocarcinoma, and undifferentiated carcinoma were classified as poorly differentiated. The depth of tumor invasion involving the mucosa, submucosa, muscularis propria, subserosa, and the serosal surface and lymph node metastasis were classified following the $14^{\text {th }}$ edition of the Gastric Cancer Treatment Protocol of the Japanese Gastric Cancer Association. Pathological staging followed the eighth edition of the American Joint Committee on Cancer tumor, node, and metastasis (TNM) staging system.

2.3. Statistical Analysis. Count data were analyzed by chisquared tests and logistic regression. Cumulative survival was analyzed and plotted by the Kaplan-Meier method; differences were evaluated with log-rank tests. Cox proportional hazard regression was used for multifactor analysis. SPSS 23.0 (IBM Corp., Armonk, NY, USA) was used for the statistical analysis, and Microsoft Excel was used for data collation. $p<0.05$ was considered statistically significant.

\section{Results}

3.1. Clinicopathological Characteristics of Upper and Lower Gastric Cancers. Patient characteristics are shown in Table 1 . The ratio of male to female patients was significantly higher in upper than in lower gastric cancer patients (4.5:1 versus $2.4: 1, p<0.001)$. The average age of upper gastric cancer patients was 61.5 years compared with 57.5 years in lower gastric cancer patients $(p=0.003)$. Three hundred and eighty-two (58.9\%) of upper gastric cancers have $\geq 5 \mathrm{~cm}$ diameter compared with 605 (39\%) of the lower gastric cancers $(p<0.001)$. Diagnosis was at an early stage in 47 (7.2\%) of upper gastric cancer patients and $332(21.4 \%, p<$ $0.001)$ of lower gastric cancer patients. The pT stages and numbers of positive lymph nodes are shown in Table 1. Fewer patients with upper (35.7\%) than lower (41.2\%) gastric cancer were lymph node negative $(p=0.046)$. The degree of differentiation of upper cancer tissues was significantly less than that of lower gastric cancers $(p=0.046)$. The growth patterns of upper and lower gastric cancers were signifi-

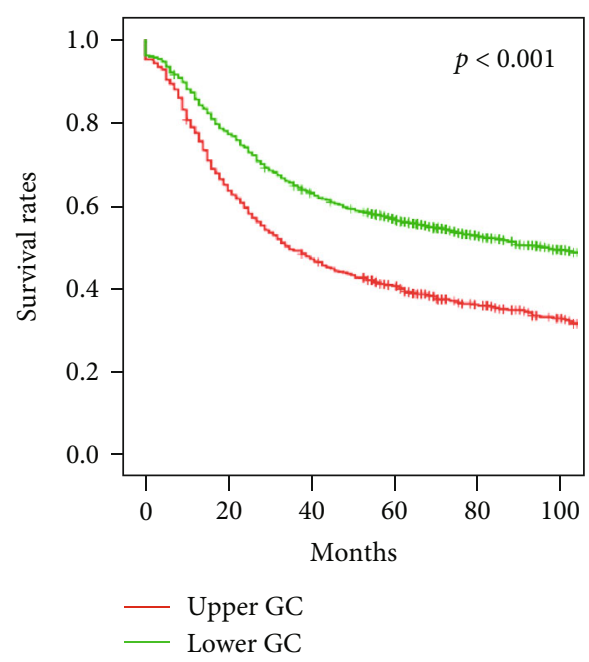

FIGURE 1: Survival of patients with upper and lower gastric cancers, $p<0.001$. Abbreviations: GC: gastric cancer.

cantly different $(p<0.001)$. Lymphovascular tumor emboli occurred in 172 of upper (26.5\%) and 346 of lower (22.3\%) gastric cancer tumors. Serosal invasion occurred in 264 of upper $(40.7 \%)$ and 375 of lower (24.2\%) gastric cancers $(p<0.001)$. Recurrence and metastasis occurred in 277 cases of upper $(42.7 \%)$ and 526 cases of lower $(33.9 \%)$ gastric cancer $(p<0.001)$.

3.2. Prognosis of Upper Gastric Cancer. The 1-year survival after radical surgery for upper gastric cancer was $77.8 \%$, 3 -year survival was $49.6 \%$, and 5 -year survival was $41.1 \%$. The 1-year survival after surgery for lower gastric cancer was $85.9 \%$, the 3 -year survival was $60.0 \%$, and the 5 -year survival was $57.2 \%(p<0.001$, Figure 1$)$. Univariate analysis showed that the tumor diameter, macroscopic type, pTNM stage, lymphovascular tumor embolus, serosal invasion, recurrence and metastasis, and postoperative adjuvant chemotherapy were associated with upper gastric cancer prognosis. Survival decreased with pTNM stage local Borrmann type 1 and 2 tumors, smaller tumor diameter, no lymphovascular tumor emboli, no serosal invasion, and no recurrence and/or metastasis. Survival was longer in patients with adjuvant chemotherapy after surgery (Figures 2 and 3). After multivariate analysis, the macroscopic tumor type, recurrence and metastasis, postoperative adjuvant chemotherapy, and pTNM staging were independently associated with upper gastric cancer prognosis (Table 2).

The characteristics of patients with and without lymph node metastasis are shown in Table 3. Metastatic lymph nodes were not found in 231 of the 649 patients with upper gastric cancer (35.6\%); 418 (64.4\%) had lymph node metastasis. The male:female ratio was $6.7: 1$ in the group without and $3.75: 1$ in the group with lymph node metastasis $(p=0.011)$. Lymph node metastasis occurred in $72.5 \%$ of patients with tumors $\geq 5 \mathrm{~cm}$ in diameter and in $52.8 \%$ of those with tumors $<5 \mathrm{~cm}$ in diameter $(p<0.001)$; in $68.9 \%$ of patients with poorly differentiated tumors and in $58.1 \%$ 


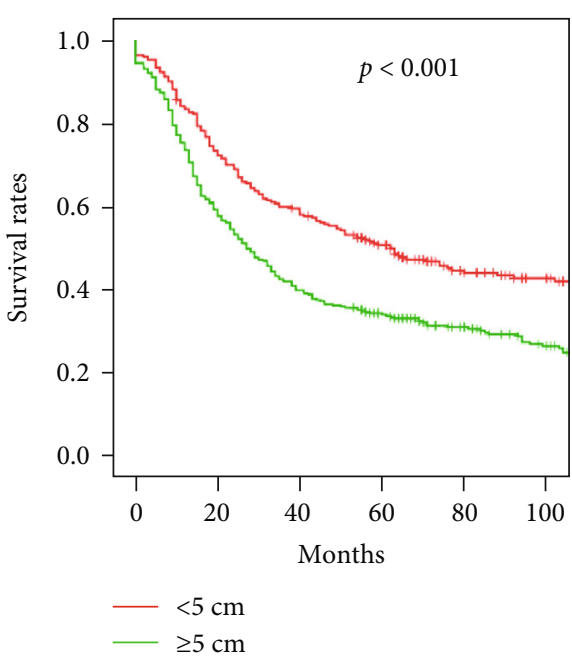

(a)

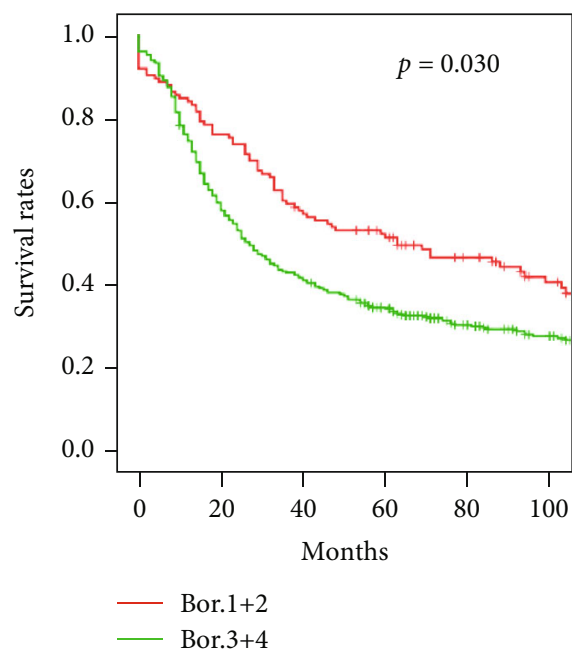

(c)

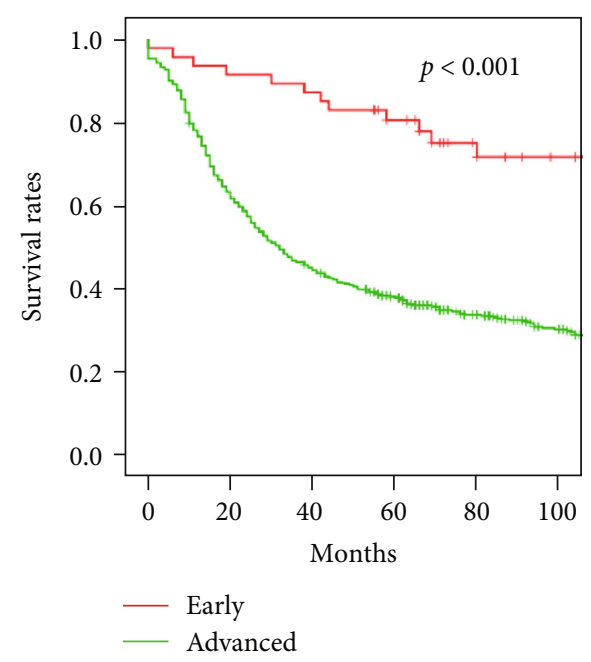

(b)

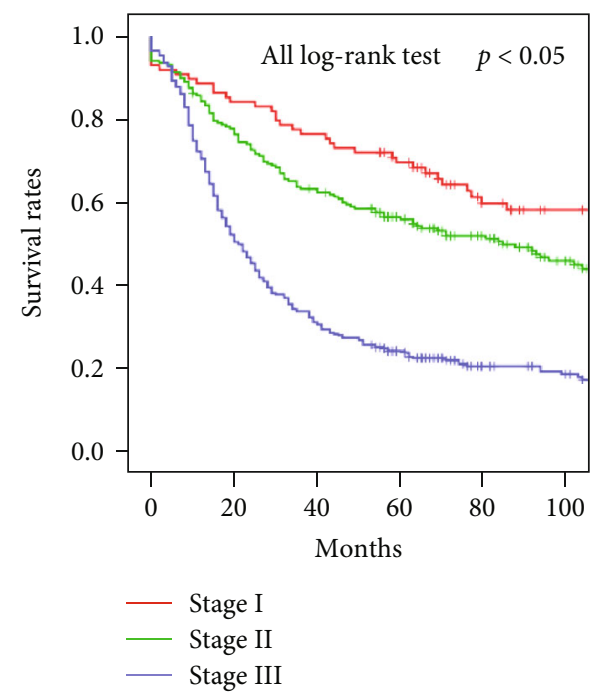

(d)

FiguRe 2: Survival of patients with upper gastric cancer: (a) tumor diameter, $p<0.001$; (b) macroscopic type, $p<0.001$; (c) Borrmann type, $p=0.030 ;(d)$ TNM stage, all log-rank test $p<0.05$.

of patients with well-differentiated tumors $(p=0.005)$; in $17.0 \%$ of early cancers and in $68.1 \%$ of advanced cancers $(p<0.001)$; and in $48.4 \%$ of patients with macroscopic local tumors and in $73.3 \%$ of infiltrative tumors $(p<0.001)$. Lymph node metastasis increased significantly with pTNM staging $(p<0.001)$. The $\mathrm{pN}$ rates are shown in Table 3 and ranged from $17.0 \%$ for $\mathrm{pT} 1$ to $79.5 \%$ for $\mathrm{pT} 4 \mathrm{~b}$ tumors. Lymph node metastasis occurred in $75.8 \%$ of patients with serosal invasion and in $56.6 \%$ of those with no serosal invasion. Patient sex, age, tissue growth mode, and lymphovascular cancer embolus were not significantly different in patients with or without lymph node metastasis. Multivariate analysis and logistic regression (Table 4) revealed that $\operatorname{sex}(p=0.036)$, tumor diameter $(p=0.001)$, macroscopic type $(p<0.001)$, pT stage $(p<0.001)$, tissue differentiation type $(p=0.003)$, and serosal invasion $(p=0.034)$ were independently associated with lymph node metastasis of upper gastric cancer.
The survival analysis of patients with and without lymph node metastasis is shown in Figure 4. The 1-year survival of the 231 patients with no lymph node metastasis was $86.1 \%$, 3 -year survival was $69.7 \%$, and 5 -year survival was $63 \%$. The corresponding survival rates for the 418 patients with lymph node metastasis were $73.2 \%, 38.4 \%$, and $28.7 \%$ $(p=0.001)$. When $\mathrm{pN}$ stage was included in the analysis, 5-year survival ranged from $63.0 \%$ for $\mathrm{pN} 0$ to $11.3 \%$ for pN3b tumors $(p<0.001)$ showing that survival decreased with increased $\mathrm{pN}$ stage. Five-year survival was ranged from $79 \%$ for $\mathrm{pT} 1$ to $22.2 \%$ for $\mathrm{pT} 4 \mathrm{~b}$ stage patients without metastatic lymph nodes. Five-year survival of patients with corresponding pT stages and metastatic lymph nodes ranged from $65.6 \%$ to $8.6 \%$.

\subsection{Postoperative Recurrence and Metastasis of Upper Gastric} Cancer. Tumor recurrence and metastasis occurred in 277 of the 649 patients with upper gastric cancer 


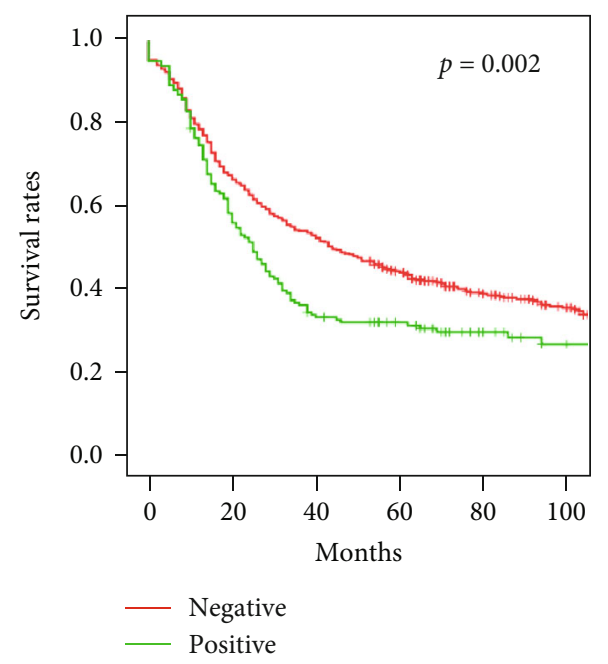

(a)

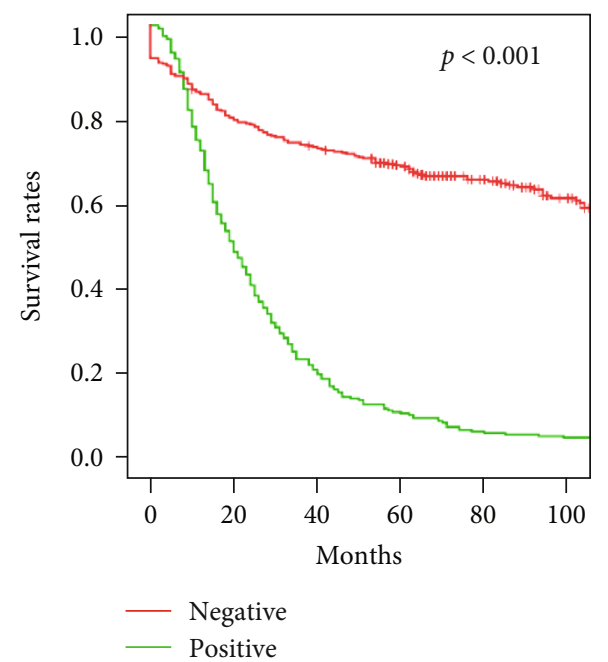

(c)

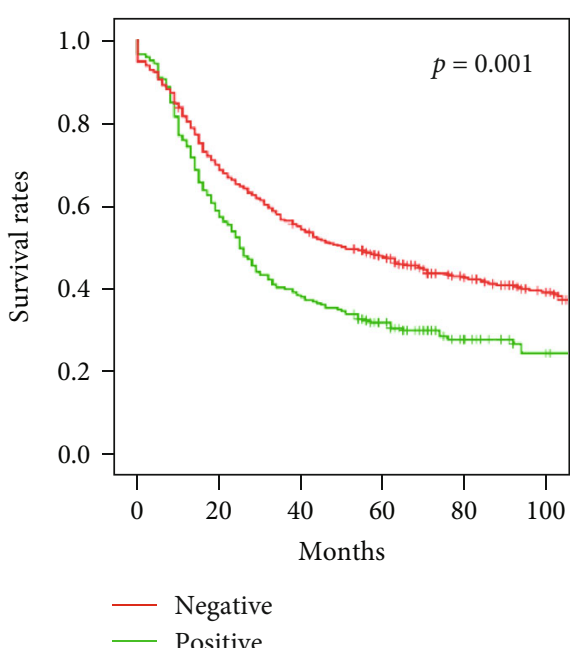

(b)

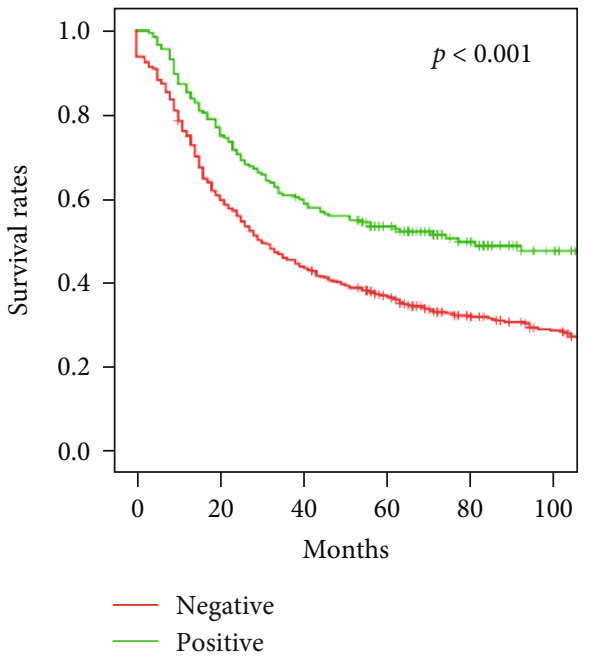

(d)

FIGURE 3: Survival of patients with upper gastric cancer: (a) lymphovascular tumor emboli, $p=0.002$; (b) serosal invasion, $p=0.001$; (c) recurrence and metastasis, $p<0.001$; (d) adjuvant chemotherapy, $p<0.001$.

TABLE 2: Multivariate analysis of tumor characteristics and upper gastric cancer prognosis.

\begin{tabular}{lcccccc}
\hline & $B$ & SE & Wald & $p$ & RR & $95 \%$ CI \\
\hline Macroscopic type & 0.264 & 0.103 & 6.603 & 0.010 & 1.302 & $1.065-1.591$ \\
Recurrence and metastasis & 1.547 & 0.112 & 190.958 & $<0.001$ & 4.695 & $3.770-5.847$ \\
Adjuvant chemotherapy & -0.548 & 0.112 & 24.078 & $<0.001$ & 0.578 & $0.464-0.719$ \\
pTNM stage & 0.343 & 0.085 & 16.206 & $<0.001$ & 1.410 & $1.193-1.666$ \\
\hline
\end{tabular}

$B$ : beta coefficient; SE: standard error of the mean; Wald: Wald statistic; RR: risk ratio; CI: confidence interval.

(42.7\%). Recurrence occurred in $47.4 \%$ of patients with tumors $\geq 5 \mathrm{~cm}$ in diameter and in $36.0 \%$ of those with tumors $<5 \mathrm{~cm} \quad(p=0.004)$. Recurrence and metastasis occurred in $12.8 \%$ of early upper gastric cancers and $45.0 \%$ of advanced stage cancers $(p<0.001) ; 28.6 \%$ of localized tumors and $49.4 \%$ of infiltrating tumors $(p<0.001) ; 52.3 \%$ of patients with lymphovascular cancer emboli and $39.2 \%$ who were thrombus-negative $(39.2 \%$, $p=0.003)$; and $50 \%$ of patients with serosal invasion compared with $37.7 \%$ of those with noninvasive tumors $(p=0.002)$. As shown in Table 5 , recurrence and metastasis increased significantly with pTNM stage, $17.8 \%$ at stage I, $27.1 \%$ at stage II, and $58.8 \%$ at stage III $(p<0.001)$. Multivariate analysis (Table 6) found that 
TABLE 3: Patient characteristics and lymph node metastasis of upper gastric cancer.

\begin{tabular}{|c|c|c|c|}
\hline & $\begin{array}{c}\text { No metastasis } \\
n=231\end{array}$ & $\begin{array}{c}\text { Metastasis } \\
n=418\end{array}$ & $p$ value \\
\hline Sex & & & 0.011 \\
\hline Male & 201 & 330 & \\
\hline Female & 30 & 88 & \\
\hline Age (years) & & & 0.936 \\
\hline$<60$ & 107 & 195 & \\
\hline$\geq 60$ & 124 & 223 & \\
\hline Tumor diameter $(\mathrm{cm})$ & & & $<0.001$ \\
\hline$<5$ & 126 & 141 & \\
\hline$\geq 5$ & 105 & 277 & \\
\hline Tissue typing & & & 0.005 \\
\hline Well differentiated & 113 & 157 & \\
\hline Poorly differentiated & 118 & 261 & \\
\hline Tissue growth mode & & & 0.166 \\
\hline Agglomerate type & 52 & 79 & \\
\hline Nest type & 72 & 113 & \\
\hline Diffuse type & 107 & 226 & \\
\hline \multicolumn{4}{|l|}{ Macroscopic type } \\
\hline Early & 39 & 8 & $<0.001$ \\
\hline Local (Borrmann 1, 2) & 65 & 61 & $<0.001^{*}$ \\
\hline Infiltrative (Borrmann 3, 4) & 127 & 349 & \\
\hline pT & & & $<0.001$ \\
\hline $\mathrm{T} 1$ & 39 & 8 & \\
\hline $\mathrm{T} 2$ & 47 & 20 & \\
\hline T3 & 81 & 190 & \\
\hline $\mathrm{T} 4 \mathrm{a}$ & 55 & 165 & \\
\hline $\mathrm{T} 4 \mathrm{~b}$ & 9 & 35 & \\
\hline Lymphovascular cancer embolus & & & 0.180 \\
\hline Positive & 54 & 118 & \\
\hline Negative & 177 & 300 & \\
\hline Serosal invasion & & & $<0.001$ \\
\hline Positive & 64 & 200 & \\
\hline Negative & 167 & 218 & \\
\hline Recurrence and metastasis & & & 0.188 \\
\hline Positive & 113 & 227 & \\
\hline Negative & 118 & 191 & \\
\hline
\end{tabular}

*Early versus advanced cancer; ${ }^{*}$ comparison of advanced cancers.

the macroscopic type $(p=0.045)$, lymphovascular tumor emboli $(p=0.021)$, and pTNM stage were independently associated with recurrence and metastasis after tumor resection.

3.4. Surgical Methods and Prognosis of Upper Gastric Cancer. D2 total gastrectomy with $1-7,8 \mathrm{a}, 9,10,11 \mathrm{p}$, or $12 \mathrm{a}$ lymph node dissection and Roux-en-Y reconstruction were performed in 333 patients. D2 proximal gastrectomy with esophagogastrostomy was performed in 281 patients, ten with jejunal interposition, and 25 with double-tract reconstruction. The spleen was preserved unless it contained metastatic lymph nodes. Better survival rates were achieved with total gastrectomy than with proximal gastrectomy $(p=0.029$, Figure 5). One-year survival of the 333 patients with D2 total gastrectomy was $81.3 \%$, 3-year survival was $54.4 \%$, and 5 -year survival was $45.2 \%$. One-year survival of the 316 proximal gastrectomy patients was $75.4 \%$, 3-year survival was $44.9 \%$, and 5-year survival rate was $36.7 \%$. In patients with tumors that had invaded the serosa, survival was better with total than with proximal gastrectomy $(p=0.045$, Figure 6(a)). Survival was also better with total than with proximal gastrectomy in patients with infiltrative type upper gastric cancer $(p=0.028$, Figure 6(b)). Differences in survival were not associated with other patient characteristics (Table 7). 
TABLE 4: Multivariate analysis of tumor characteristics and lymph node metastasis in upper gastric cancer.

\begin{tabular}{|c|c|c|c|c|c|c|}
\hline & $B$ & SE & Wald & $p$ value & RR & $95 \% \mathrm{CI}$ \\
\hline Sex & -0.433 & 0.206 & 4.419 & 0.036 & 0.648 & $0.433-0.971$ \\
\hline Tumor diameter & 0.570 & 0.166 & 11.837 & 0.001 & 1.768 & $1.278-2.447$ \\
\hline Macroscopic type & 0.639 & 0.157 & 16.610 & $<0.001$ & 1.894 & $1.393-2.575$ \\
\hline pT stage & 0.739 & 0.170 & 18.833 & $<0.001$ & 2.095 & $1.500-2.925$ \\
\hline Tissue typing & 0.442 & 0.147 & 9.075 & 0.003 & 1.556 & $1.167-2.074$ \\
\hline Serosal invasion & -0.575 & 0.271 & 4.499 & 0.034 & 0.562 & $0.330-0.957$ \\
\hline
\end{tabular}

$B$ : beta coefficient; SE: standard error of the mean; Wald: Wald statistic; RR: risk ratio; CI: confidence interval.

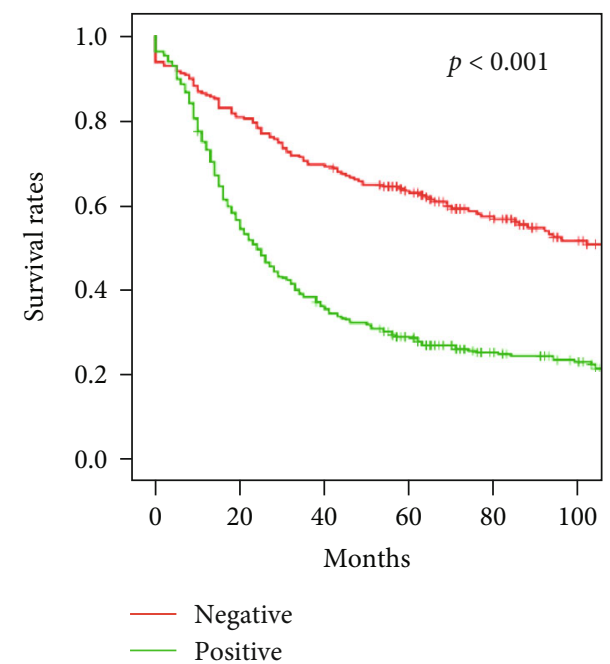

FIGURE 4: Survival of upper gastric cancer patients with and without lymph node metastasis, $p<0.001$.

Twenty-one patients with total gastrectomy (6.3\%) and 36 with proximal gastrectomy $(11.4 \%)$ had postoperative complications. Five total gastrectomy patients experienced wound infections, three developed pneumonia, and two experienced fluid esophagitis; and intestinal obstruction, abdominal infection, and pancreatic fistula occurred in one patient each. There were seven occurrences of diarrhea, anemia, pneumothorax, and dumping syndrome. Wound infections and anastomotic leakage each occurred in eight proximal gastrectomy patients, five patients developed pneumonia, and four experienced reflux esophagitis. There were three cases of intestinal obstruction, three of abdominal infection, and two of pancreatic fistula. There were ten reports of diarrhea, anemia, pneumothorax, emphysema, and heart failure.

\section{Discussion}

The biological behavior of tumors determines the occurrence, development, and pathological features of tumors. It is a sign of the nature and malignancy of tumors. The gastric cancer in different parts has great differences in biological behavior. The macroscopic type, growth pattern, and degree of tissue typing of gastric cancer can correctly reflect the biological behavior of gastric cancer, and it is a sign of malignant accumulation and invasive expansion of gastric cancer.

Diagnosis of early stage disease has been reported in only $4.3 \%$ of patients with upper gastric cancer [13], which is significantly less frequent than in patients with lower gastric cancer. In this series, $7.2 \%$ of the upper gastric cancers were found at an early stage, which was significantly lower than the $21.4 \%$ of early lower gastric cancer diagnoses. The proportion of tumors that were $\geq 5 \mathrm{~cm}$ was significantly greater in patients with upper than with lower gastric cancer; more upper than lower gastric cancer tumors were poorly differentiated. The pT stage was significantly more advanced in upper than in lower gastric cancers; infiltration was deeper; and $\mathrm{pN}$ stage, proportion of tumors with lymphovascular emboli, and the proportion of tumors with serosal invasion were all higher. Recurrence and metastasis after surgery were also more frequent in patients with upper than with lower gastric cancer.

The study results are consistent with previous findings that survival is worse with upper than with lower gastric cancer. In this series, 5-year survival was $41.1 \%$ in upper gastric cancer compared with $57.2 \%$ in lower gastric cancer patients (Figure 1), which is comparable to the $40 \% 5$-year survival reported by others $[14,15]$. Univariate analysis showed that the tumor diameter, macroscopic type, pTNM stage, lymphovascular tumor emboli, serosal invasion, tumor recurrence and metastasis, and postoperative adjuvant chemotherapy all affected the prognosis of upper gastric cancer. Five-year survival was $50.9 \%$ when the tumor diameter was $<5 \mathrm{~cm}$ and $34.1 \%$ when it was $\geq 5 \mathrm{~cm}$; $77.9 \%$ for early and $38.0 \%$ for advanced disease; $51.4 \%$ for local and $34.2 \%$ for infiltrative tumors; $44.3 \%$ in the absence of and $31.4 \%$ in the presence of lymphovascular tumor emboli; $30.3 \%$ with and $47.5 \%$ without serosal invasion; $7.2 \%$ with and $66.2 \%$ without recurrence and metastasis; and $52.3 \%$ with and $36.0 \%$ without adjuvant therapy. Five-year survival also significantly decreased from $69.8 \%$ to $24.0 \%$ with the increase of pTNM stage from I to III. Multivariate analysis found that the macroscopic type, recurrence and metastasis, postoperative adjuvant chemotherapy, and pTNM stage were all independently associated with the prognosis of upper gastric cancer.

Most upper gastric cancers are diagnosed at a more advanced stage than lower gastric cancers; few cases of early 
TABLE 5: Patient characteristics and recurrence and metastasis of upper gastric cancer.

\begin{tabular}{|c|c|c|c|}
\hline & $\begin{array}{l}\text { Recurrence and metastasis } \\
\qquad n=277\end{array}$ & $\begin{array}{l}\text { No recurrence and metastasis } \\
\qquad n=372\end{array}$ & $p$ value \\
\hline$\overline{\text { Sex }}$ & & & 0.246 \\
\hline Male & 221 & 310 & \\
\hline Female & 56 & 62 & \\
\hline Age (years) & & & 0.987 \\
\hline$<60$ & 129 & 173 & \\
\hline$\geq 60$ & 148 & 199 & \\
\hline Tumor diameter $(\mathrm{cm})$ & & & 0.004 \\
\hline$<5$ & 96 & 171 & \\
\hline$\geq 5$ & 181 & 201 & \\
\hline Tissue typing & & & 0.099 \\
\hline Well differentiated & 105 & 165 & \\
\hline Poorly differentiated & 172 & 207 & \\
\hline Tissue growth mode & & & 0.473 \\
\hline Agglomerate type & 58 & 73 & \\
\hline Nest type & 72 & 113 & \\
\hline Diffuse type & 147 & 186 & \\
\hline \multicolumn{4}{|l|}{ Macroscopic type } \\
\hline Early & 6 & 41 & $<0.001$ \\
\hline Local (Borrmann 1, 2) & 36 & 90 & $<0.001^{*}$ \\
\hline Infiltrative (Borrmann 3, 4) & 235 & 241 & \\
\hline Lymphovascular cancer embolus & & & 0.003 \\
\hline Positive & 90 & 82 & \\
\hline Negative & 187 & 290 & \\
\hline Serosal invasion & & & 0.002 \\
\hline Positive & 132 & 132 & \\
\hline Negative & 145 & 240 & \\
\hline Adjuvant chemotherapy & & & 0.412 \\
\hline Positive & 186 & 261 & \\
\hline Negative & 91 & 111 & \\
\hline pTNM stage & & & $<0.001$ \\
\hline I & 16 & 74 & \\
\hline II & 58 & 156 & \\
\hline III & 203 & 142 & \\
\hline
\end{tabular}

*Early versus advanced cancer; ${ }^{*}$ comparison of advanced cancers.

TABLE 6: Multivariate analysis of tumor characteristics and recurrence and metastasis of upper gastric cancer.

\begin{tabular}{lcccccc}
\hline & $B$ & SE & Wald & $p$ value & RR & $95 \%$ CI \\
\hline Macroscopic type & 0.379 & 0.189 & 4.003 & 0.045 & 1.460 & $1.008-2.116$ \\
Lymphovascular tumor emboli & 0.440 & 0.191 & 5.287 & 0.021 & 1.552 & $1.067-2.258$ \\
pTNM typing & 0.966 & 0.149 & 42.105 & $<0.001$ & 2.628 & $1.963-3.519$ \\
\hline
\end{tabular}

$B$ : beta coefficient; SE: standard error of the mean; Wald: Wald statistic; RR: risk ratio; CI: confidence interval.

disease are detected. The macroscopic type is generally infiltrative, the tumor diameter is large, and the tissue is poorly differentiated and has invaded the serosa. Lymph node metastasis, late pTNM stage, and recurrence and metastasis after surgery are the main contributors to a worse prognosis than that of lower gastric cancer. Adjuvant chemotherapy is known to increase the effectiveness of surgery in advanced gastric cancer [16-22]. Five-year survival was $52.3 \%$ in patients with adjuvant chemotherapy compared with $36.0 \%$ in those who did not receive it, which supports a 


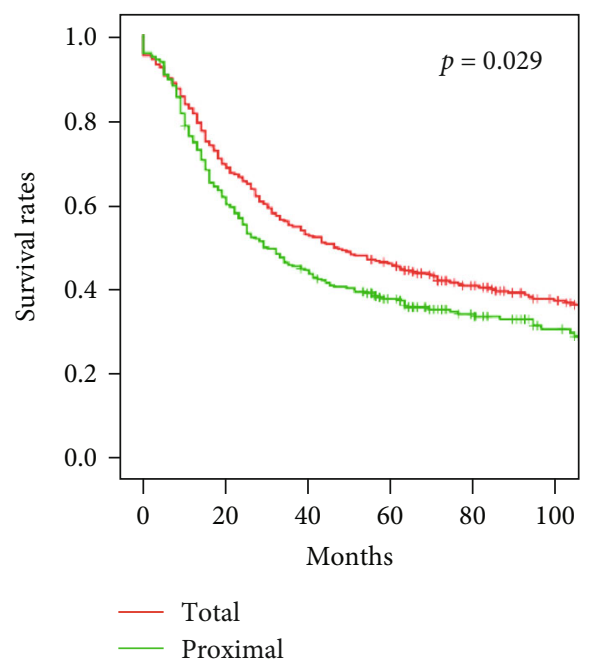

FIGURE 5: Survival of upper gastric cancer patients treated by total or proximal gastrectomy, $p=0.029$.

recommendation for adjuvant chemotherapy in upper gastric cancer patients following resective surgery.

Lymph node metastasis has a poor prognosis in gastric cancer, which makes the removal of a sufficient number of regional lymph nodes an important component of radical surgery. Five-year survival was $28.7 \%$ in patients with and $63 \%$ in those without lymph node metastasis. The finding of lymph node metastasis in $64.3 \%$ of upper gastric cancer patients compared with $58.8 \%$ of those with lower gastric cancer is consistent with previous reports [23]. In this study, male sex, tumors $\geq 5 \mathrm{~cm}$, poor tumor differentiation, macroscopic infiltration, and serosal invasion were more frequent in patients with lymph node metastasis. Statistical analysis found that sex, tumor diameter, macroscopic type, $\mathrm{pT}$ stage, tissue growth pattern, and serosal invasion were independent risk factors for lymph node metastasis of upper gastric cancer.

Gastric cancer recurs in situ or with lymph node, peritoneal, or liver metastasis or with hematogenous spread outside the liver with metastasis to other locations. Postoperative recurrence and metastasis may be related to tumor characteristics such as size, tissue type, differentiation, growth mode, pTNM staging, the extent of radical surgery, lymph node dissection, and intraoperative spread of cancer cells [24, 25]. Gastric cancer prognosis includes a high risk of recurrence and metastasis after radical gastrectomy [26]. Recurrence after radical gastrectomy is estimated to occur in approximately 50\% [27], to more than $70 \%$ of patients with lymph node metastasis at diagnosis [28]. In this study, recurrence and metastasis occurred in $42.7 \%$ of upper gastric cancers and in $33.9 \%$ of lower gastric cancers. Recurrence and metastasis in patients with upper gastric cancer and preoperative lymph node metastasis were $54.3 \%$, which is lower than previously reported. One-year survival of patients with postoperative recurrence and metastasis was $70.0 \%$; the 3 -year survival was $20.2 \%$; and the 5-year survival was $7.2 \%$, all of which were lower than the $83.6 \%, 71.5 \%$, and $66.2 \%$ survival of patients without recurrence and metastasis, respectively. Recurrence and metastasis were more frequent in patients with tumors $\geq 5 \mathrm{~cm}$, macroscopic infiltration, lymphovascular tumor emboli, serosal invasion, and increased pTNM stage. The macroscopic type, lymphovascular tumor emboli, and pTNM stage were independently associated with recurrence and metastasis.

Radical surgery is recommended by the Japanese Gastric Cancer Association Classification of Gastric Carcinoma fifteenth edition. D2 radical lymph node dissection is recommended, but differences of surgical procedures result in differences of the number of lymph nodes collected. It is still not clear whether total gastrectomy or proximal gastrectomy is preferred [29]. Total gastrectomy achieves sufficient resection and a wide range of lymph node dissection. Proximal gastrectomy preserves part of the stomach, allowing reconstruction of the digestive tract and better physiological recovery [30]. In upper gastric cancer surgery, dissection of lymph nodes 10 and $11 \mathrm{~b}$ in the second station involves consideration of the spleen and possibly pancreatic body resection. However, two European randomized trials found that D2 surgery with spleen resection did not provide a survival benefit but rather increased the incidence of postoperative complications and mortality $[11,31]$. A study by the Japan Clinical Oncology Group (JCOG0110) that compared splenectomy and spleen-preserving surgery did not find a significant difference in the 5-year survival in a group of over 500 gastric cancer patients $(75.1 \%$ vs. $76.4 \%)$. The incidence of postoperative complications was higher in the splenectomy group $(30.3 \%)$ than in the spleen-preserving group $(6.7 \%, p<0.05)$. Splenectomy should be avoided in patients with total gastrectomy for upper gastric cancer that does not involve the greater curvature and is without splenic lymph node metastasis. In such patients, splenectomy increases the occurrence of complications without increasing survival [32]. Neither the Japanese gastric treatment guidelines nor the National Comprehensive Cancer Network recommends prophylactic splenectomy [33]. The JCOG9501 study, which included patients who were at high risk, found an $8.4 \%$ incidence of No. 10 lymph node metastasis [34]. Whether splenectomy can improve survival in patients at risk of lymph node 10 metastasis because of the extent of local invasion, invasion of the greater curvature, or clinical suspicion of lymph node 10 metastasis deserves study.

4.1. Study Strengths and Limitations. The strengths include a relatively large sample size, which increased the statistical power. The retrospective design is a limitation, as the data may lack variables that could affect the results.

\section{Conclusion}

Upper and lower gastric cancer patients differed in sex, age, tumor diameter, tissue type, growth pattern, macroscopic type, infiltration depth, degree of lymph node metastasis, lymphovascular tumor emboli, and postoperative tumor recurrence and metastasis. Upper gastric cancers were more 


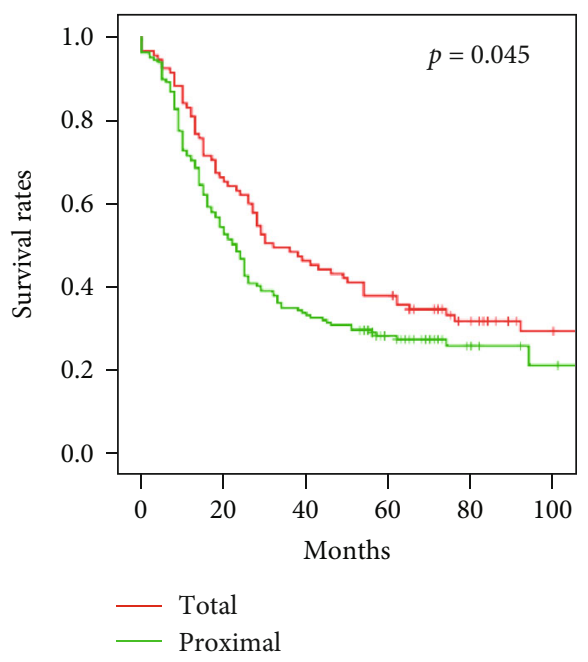

(a)

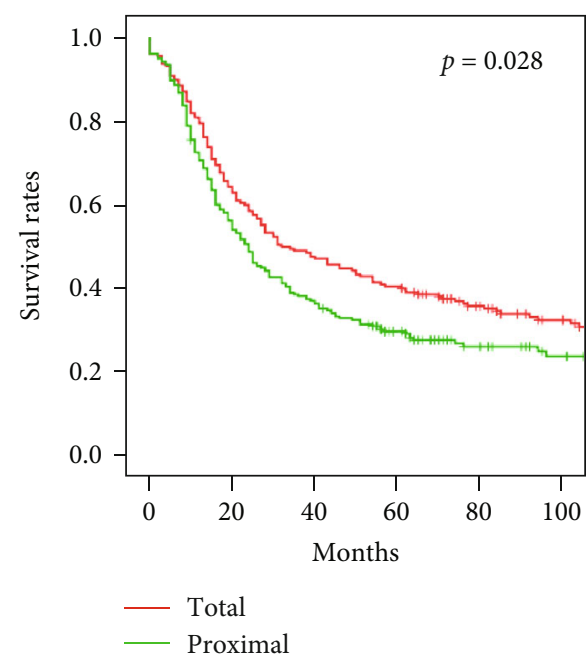

(b)

Figure 6: Survival of patients with upper gastric cancer and treated by total or proximal gastrectomy. (a) Invasion of the serosa, $p=0.045$; (b) Borrmann type 3 or 4 infiltration, $p=0.028$.

TABLE 7: One-, 3-, and 5-year survival of upper gastric cancer patients with total or proximal gastrectomy.

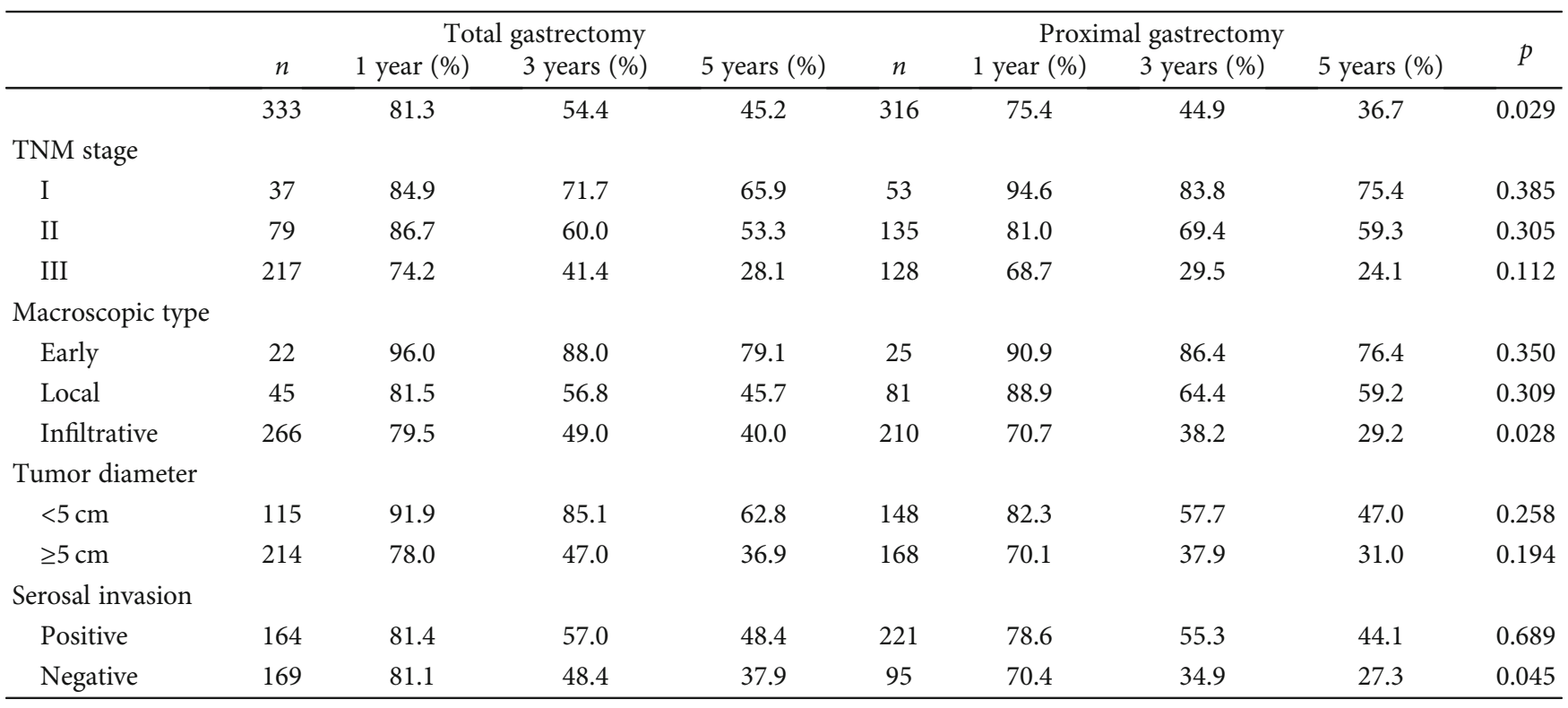

aggressive, had a worse prognosis, and were more prone to recurrence and metastasis after radical gastrectomy than lower gastric cancers. Surgical treatment of upper gastric cancer by radical total gastrectomy achieved better survival radical proximal resection.

\section{Data Availability}

This study data is from the "Department of Surgical Oncology, The First Affiliated Hospital of China Medical University, Shenyang (110001), China," and from patients with gastric cancer who underwent R0 resection for gastric cancer at The First Affiliated Hospital of China Medical University from January 1980 to December 2012. Raw data cannot be provided for personal and commercial purposes.

\section{Ethical Approval}

The study was approved by institutional review board of China Medical University.

\section{Consent}

Every patient provided written informed consent before enrollment. 


\section{Conflicts of Interest}

The authors declare that they have no conflicts of interest.

\section{Authors' Contributions}

Yingbo Gong and Huimian Xu made substantial contributions to the conception or design of the study and drafted the manuscript. Pengliang Wang and Zhi Zhu contributed to statistics and analysis of the data and revised the manuscript. Junyan Zhang and Jinyu Huang participated in data collection and literature research. All authors read and approved the final manuscript.

\section{Acknowledgments}

We thank International Science Editing (http://www internationalscienceediting.com) for editing this manuscript. This study was supported by the National Natural Science Foundation of China (Grant No. 81772549 and No. 81572334).

\section{References}

[1] F. Bray, J. Ferlay, I. Soerjomataram, R. L. Siegel, L. A. Torre, and A. Jemal, "Global cancer statistics 2018: GLOBOCAN estimates of incidence and mortality worldwide for 36 cancers in 185 countries," CA: A Cancer Journal for Clinicians, vol. 68, no. 6, pp. 394-424, 2018.

[2] J. C. Salvon-Harman, B. Cady, S. Nikulasson, U. Khettry, M. D. Stone, and P. Lavin, "Shifting proportions of gastric adenocarcinomas," Archives of Surgery, vol. 129, no. 4, pp. 381-389, 1994.

[3] D. Forman, "Review article: oesophago-gastric adenocarcinoma - an epidemiological perspective," Alimentary Pharmacology \& Therapeutics, vol. 20, pp. 55-60, 2004.

[4] S. Ishikawa, S. Shimada, N. Miyanari, M. Hirota, H. Takamori, and H. Baba, "Pattern of lymph node involvement in proximal gastric cancer," World Journal of Surgery, vol. 33, no. 8, pp. 1687-1692, 2009.

[5] C. Deans, M. S. W. Yeo, M. Y. Soe, A. Shabbir, T. K. Ti, and J. B. Y. So, "Cancer of the gastric cardia is rising in incidence in an Asian population and is associated with adverse outcome," World Journal of Surgery, vol. 35, no. 3, pp. 617-624, 2011.

[6] C. Kunisaki, H. Shimada, H. Ono et al., "Comparison of results of surgery in the upper third and more distal stomach," Journal of Gastrointestinal Surgery, vol. 10, no. 5, pp. 718-726, 2006.

[7] K. Mikami, T. Maekawa, T. Shinohara et al., "Predictive factors of early recurrent death after a curative resection of gastric cancer," International Surgery, vol. 94, no. 2, pp. 144-148, 2009.

[8] P. Piso, U. Werner, H. Lang, P. Mirena, and J. Klempnauer, "Proximal versus distal gastric carcinoma-what are the differences?," Annals of Surgical Oncology, vol. 7, no. 7, pp. 520-525, 2000.

[9] C. Mariette, B. Castel, H. Toursel, S. Fabre, J. M. Balon, and J. P. Triboulet, "Surgical management of and long-term survival after adenocarcinoma of the cardia," British Journal of Surgery, vol. 89, no. 9, pp. 1156-1163, 2002.
[10] S. P. Stark, M. S. Romberg, G. E. Pierce et al., "Transhiatal versus transthoracic esophagectomy for adenocarcinoma of the distal esophagus and cardia," American Journal of Surgery, vol. 172, no. 5, pp. 478-482, 1996.

[11] J. J. Bonenkamp, I. Songun, K. Welvaart et al., "Randomised comparison of morbidity after D1 and D2 dissection for gastric cancer in 996 Dutch patients," The Lancet, vol. 345, no. 8952, pp. 745-748, 1995.

[12] L. E. Harrison, M. S. Karpeh, and M. F. Brennan, "Total gastrectomy is not necessary for proximal gastric cancer," Surgery, vol. 123, no. 2, pp. 127-130, 1998.

[13] H. Maeda, T. Okabayashi, I. Nishimori et al., "Clinicopathologic features of adenocarcinoma at the gastric cardia: is it different from distal cancer of the stomach?," Journal of the American College of Surgeons, vol. 206, no. 2, pp. 306-310, 2008.

[14] N. Amini, G. Spolverato, Y. Kim et al., "Clinicopathological features and prognosis of gastric cardia adenocarcinoma: a multi-institutional U.S. study," Journal of Surgical Oncology, vol. 111, no. 3, pp. 285-292, 2015.

[15] Q. Huang, Q. Sun, X. S. Fan, D. Zhou, and X. P. Zou, "Recent advances in proximal gastric carcinoma," Journal of Digestive Diseases, vol. 17, no. 7, pp. 421-432, 2016.

[16] J. A. Ajani, J. Fairweather, P. Dumas, Y. Z. Patt, R. Pazdur, and P. F. Mansfield, "Phase II study of Taxol in patients with advanced gastric carcinoma," The Cancer Journal from Scientific American, vol. 4, pp. 269-274, 1988.

[17] A. I. Einzig, D. Neuberg, S. C. Remick et al., "Phase II trial of docetaxel (Taxotere) in patients with adenocarcinoma of the upper gastrointestinal tract previously untreated with cytotoxic chemotherapy: the Eastern Cooperative Oncology Group (ECOG) results of protocol E1293," Medical Oncology, vol. 13, no. 2, pp. 87-93, 1996.

[18] K. Futatsuki, A. Wakui, I. Nakao et al., "Late phase II study of irinotecan hydrochloride (CPT-11) in advanced gastric cancer. CPT-11 Gastrointestinal Cancer Study Group," Cancer \& Chemotherapy, vol. 21, pp. 1033-1038, 1994.

[19] T. Taguchi, S. Tsukagoshi, H. Furue, H. Niitani, and K. Noda, "Phase I clinical study of oxaliplatin," Cancer \& Chemotherapy, vol. 25, pp. 1899-1907, 1998.

[20] Y. Sakata, A. Ohtsu, N. Horikoshi, K. Sugimachi, Y. Mitachi, and T. Taguchi, "Late phase II study of novel oral fluoropyrimidine anticancer drug S-1 (1 M tegafur- $0.4 \mathrm{M}$ gimestat- $1 \mathrm{M}$ otastat potassium) in advanced gastric cancer patients," European Journal of Cancer, vol. 34, no. 11, pp. 1715-1720, 1998.

[21] C. Liu, Q. Sun, X. Hang, B. Zhong, and D. Wang, "Multicenter phase II study of capecitabine plus oxaliplatin as a first-line therapy in Chinese patients with advanced gastric cancer," Anti-Cancer Drugs, vol. 19, no. 8, pp. 825-831, 2008.

[22] T. Ichikura, T. Ogawa, K. Chochi, T. Kawabata, H. Sugasawa, and H. Mochizuki, "Minimum number of lymph nodes that should be examined for the International Union Against Cancer/American Joint Committee on Cancer TNM classification of gastric carcinoma," World Journal of Surgery, vol. 27, no. 3, pp. 330-333, 2003.

[23] Y. Y. Xu, B. J. Huang, Z. Sun, C. Lu, and Y. P. Liu, "Risk factors for lymph node metastasis and evaluation of reasonable surgery for early gastric cancer," World Journal of Gastroenterology, vol. 13, no. 38, pp. 5133-5138, 2007.

[24] E. Otsuji, S. Kobayashi, K. Okamoto, A. Hagiwara, and H. Yamagishi, "Is timing of death from tumor recurrence 
predictable after curative resection for gastric cancer?," World Journal of Surgery, vol. 25, no. 11, pp. 1373-1376, 2001.

[25] B. Sakar, H. Karagol, M. Gumus et al., "Timing of death from tumor recurrence after curative gastrectomy for gastric cancer," American Journal of Clinical Oncology, vol. 27, no. 2, pp. 205-209, 2004.

[26] N. L. Solomon, M. C. Cheung, M. M. Byrne et al., "Does chemoradiotherapy improve outcomes for surgically resected adenocarcinoma of the stomach or esophagus?," Annals of Surgical Oncology, vol. 17, no. 1, article 679, pp. 98-108, 2010.

[27] T. S. Liu, Y. Wang, S. Y. Chen, and Y. H. Sun, “An updated meta-analysis of adjuvant chemotherapy after curative resection for gastric cancer," European Journal of Surgical Oncology, vol. 34, no. 11, pp. 1208-1216, 2008.

[28] J. S. Macdonald, “Treatment of localized gastric cancer," Seminars in Oncology, vol. 31, no. 4, pp. 566-573, 2004.

[29] J. Y. An, H. G. Youn, M. G. Choi, J. H. Noh, T. S. Sohn, and S. Kim, "The difficult choice between total and proximal gastrectomy in proximal early gastric cancer," American Journal of Surgery, vol. 196, no. 4, pp. 587-591, 2008.

[30] A. Ooki, K. Yamashita, S. Kikuchi et al., "Clinical significance of total gastrectomy for proximal gastric cancer," Anticancer Research, vol. 28, no. 5B, pp. 2875-2883, 2008.

[31] A. Cuschieri, V. Joypaul, P. Fayers et al., "Postoperative morbidity and mortality after D1 and D2 resections for gastric cancer: preliminary results of the MRC randomised controlled surgical trial," The Lancet, vol. 347, no. 9007, pp. 995-999, 1996.

[32] T. Sano, M. Sasako, J. Mizusawa et al., "Randomized controlled trial to evaluate splenectomy in total gastrectomy for proximal gastric carcinoma," Annals of Surgery, vol. 265, no. 2, pp. 277$283,2017$.

[33] Japanese Gastric Cancer Association, "Japanese gastric cancer treatment guidelines 2014 (ver. 4)," Gastric Cancer, vol. 20, no. 1, pp. 1-19, 2017.

[34] M. Sasako, T. Sano, S. Yamamoto et al., "D2 lymphadenectomy alone or with para-aortic nodal dissection for gastric cancer," The New England Journal of Medicine, vol. 359, no. 5, pp. 453-462, 2008. 


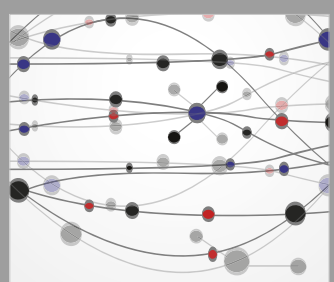

The Scientific World Journal
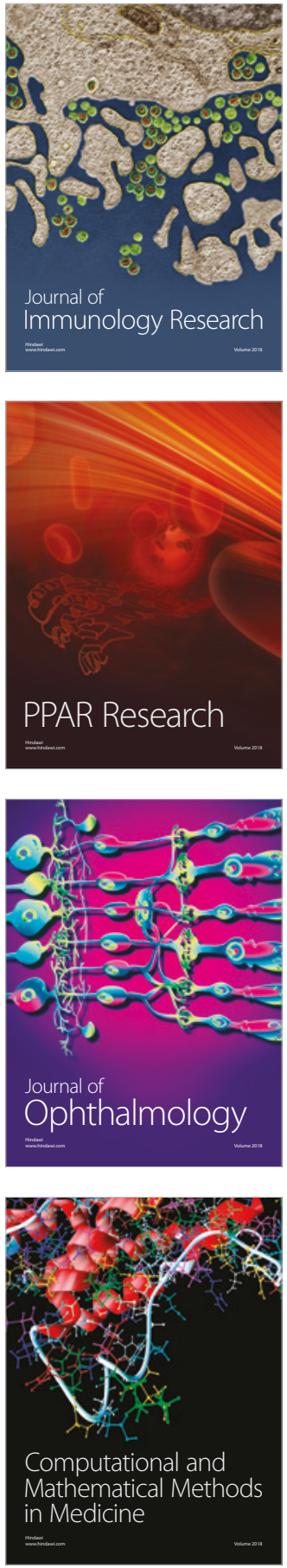

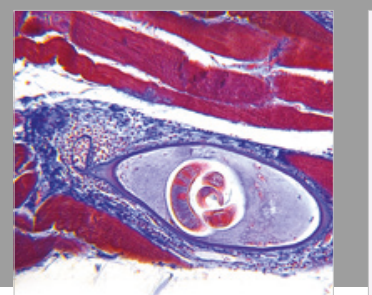

Gastroenterology Research and Practice

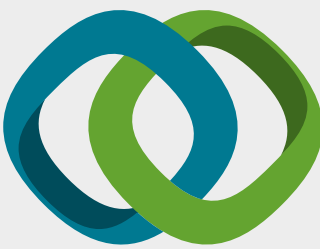

\section{Hindawi}

Submit your manuscripts at

www.hindawi.com
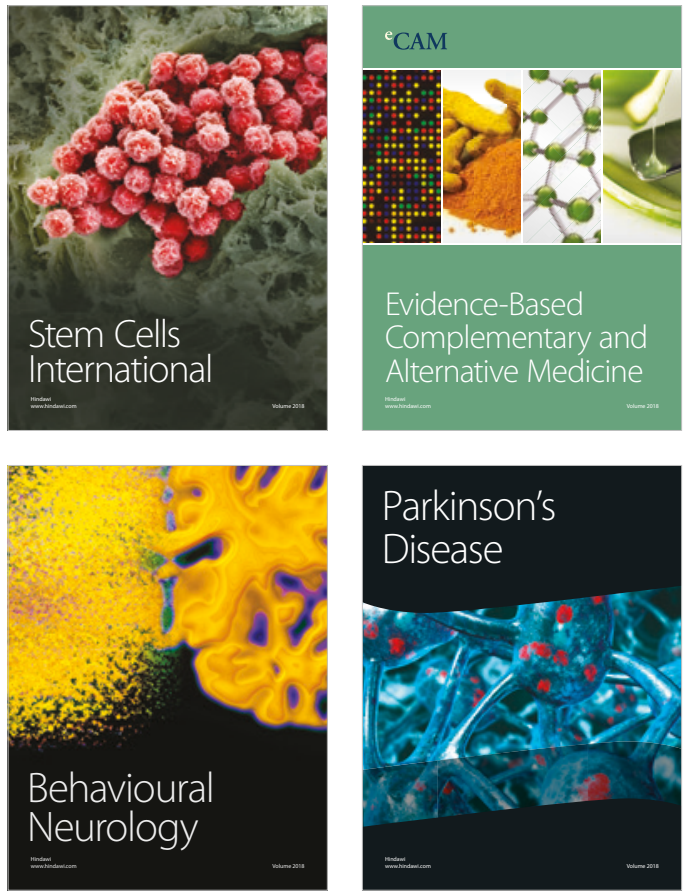

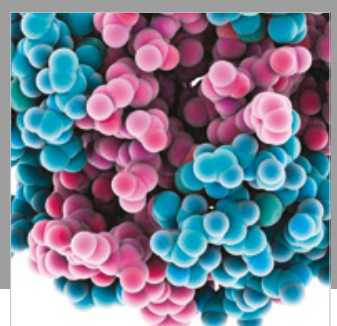

ournal of

Diabetes Research

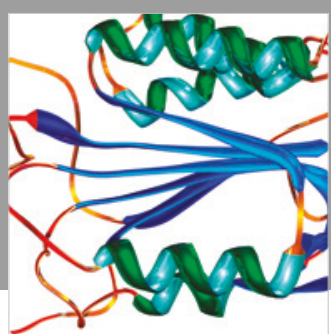

Disease Markers
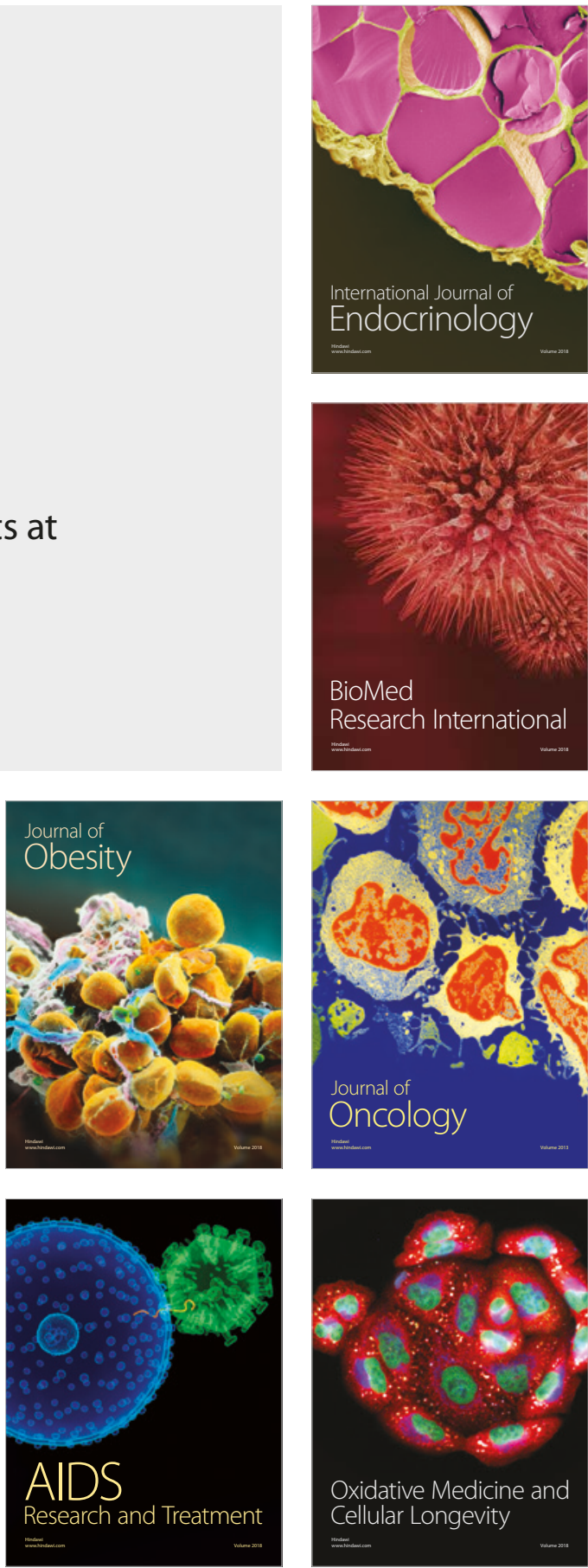